\title{
ENSEÑANZA DE LA MÚSICA EN LAS CATEDRALES
}

\author{
SUMARIO
}

1. Los niños de coro: historia de una institución secular

2. Una pedagogía musical para niños cantores

\section{LOS NIÑOS DE CORO: HISTORIA DE UNA INSTITUCIÓN SECULAR}

En este primer apartado vamos a fijar, de modo preferente, nuestra atención en tres puntos clave sobre los que gira la vida institucional de esta pequeña comunidad cantora: el maestro educador, el niño de coro o infante y los estatutos catedralicios reguladores, en un ámbito macrorganizado, de esta parcela de la vida capitular.

La tradición visigótico-mozárabe mantiene la función y el nombre establecidos por San Isidoro de Sevilla, bien atento a su origen etimológico:

Praecentor qui vocem praemittit in cantu; succentor autem qui subsequenter canendo respondit. Concentor autem dicitur quia consonat.

El precentor, una vez que se va imponiendo definitivamente en los siglos XII y XIII la liturgia romana frente al rito mozárabe en España, mantiene el nombre y oficio, como director y responsable del coro, delegando en el sucentor o doblero suyo para cometidos más técnicos mientras que el concentor o resto del coro actúa alternando en la salmodia a partir de la mano derecha o izquierda del deán, o del obispo si asiste, como presidentes de la liturgia. Posteriormente empezarán también en los estatutos catedralicios a identificarse los nombres de precentor con el de chantre y el de sucentor con el de sochantre bajo una acusada influencia francesa.

La entrada paulatina en la segunda mitad del siglo XIII en la música profana de la técnica fabordonada (faux bourdon), de las polifonías simples de

' ML, 82, 292. 
los "carmina burana» de los goliardos o de las cantatas palatinas, bajo la influencia, entre nosotros, de la nueva musicalización instrumental de las cantigas o de los cantos de peregrinos, hace surgir en las catedrales las «scholae cantorum» o pequeñas capillas de cantores que alivian la monotonía del coro. A este propósito señala puntualmente en las Partidas Alfonso X el Sabio:

..E algunas eglesias cathedrales son en que y a cabiscoles que han este mesmo officio que los chantres; e cabiscol quiere tanto decir como cabdillo de el coro, para levantar los cantos.. ?.

Observamos que el precentor, chantre o capiscol no sólo dirije la salmodia unísona sino el grupo de cantores inicialmente polifónico. Los términos capiscol y cabiscol de unas citas y los de capiscor y cabiscor en otras, dentro de los estatutos catedralicios, se reservan siempre para el cabeza de la «schola cantorum» y no para el maestrescuela en relación con la escuela de gramática, como algunas veces se interpreta. Junto a estos nombres también aparecen los de "primicerius» y "primiclerus», el de "paraphonista o choripauta» o simplemente el de "cantor" sin que en todos los casos puedan identificarse con los primeros, según los estudios de Higinio Anglès ".

Los nombres más frecuentes de los niños colocados al servicio del canto en las catedrales españolas son los de mozos de coro, niños de coro, seises, infantes y coloradillos. Tratar de adscribir, de modo definitivo, cualquiera de estos términos a una determinada zona de la geografía eclesiástica o a una específica función cultural no sería correcto, pues en todas las citas que aportamos sobre el tema se utilizan indistintamente cualquiera de estos vocablos. Pero en un intento de aproximarnos a una razonable, aunque provisional, justificación sobre el uso preferente de varios de estos nombres hemos de apoyarnos en algunos criterios de algún modo determinantes.

La primera legislación catedralicia utiliza con frecuencia el nombre de "pueri cantores» mientras que los estatutos posteriores al siglo XIV, y redactados ya en castellano, utilizan el término de «mozos de coro». Desde el ámbito geográfico la palabra «seises» se utiliza, incluyendo el matiz de la danza sacramental, en las diócesis de Andalucía y en Toledo, mientras que el vocablo «infantes» es más frecuente en las diócesis de Aragón y el de «niños cantores» en las de Santiago. Desde un criterio puramente técnico encontramos los términos de "tiples", "altos o contraltos», pero si atendemos al hecho de la institucionalización reparamos siempre en el título de "Colegios de Infantes», lo mismo que por el color de la ropa reciben los niños el mote de "coloradillos» y por la edad, tal vez, el de «cantorcicos»; pero ciertamente el nombre popular,

2 Alfonso el Sabio, Partidas, 1.2. t. 6, leg. 5.

3 H.ANGlès, La Música a Calatunya fins al segle XIII, Barcelona 1935, 40-63. 
que hemos adoptado en el trabajo, es el de "niños de coro».

El número de los niños seleccionados en cada catedral, para el canto litúrgico y la previa enseñanza, no era fijo sino supeditado a la situación económica de cada cabildo o a las exigencias de la capilla musical correspondiente. Entre los 12 infantes que registran los primeros estatutos de Burgos o Ávila en $1250^{\circ} \mathrm{y}$ los 2 niños clérigos de Segorbe 'se dan cifras diferentes, pero el número de 6, justificante del nombre seises, era el más corriente o el ideal. La edad de los niños, oscilante entre los seis y trece años, estaba condicionada por el proceso evolutivo del niño hasta la tercera infancia, siempre coincidente con el cambio de voz.

El origen social de los niños de coro es fácilmente detectable a través de los expedientes de ingreso en el coro.

Muchas veces son hijos de servidores de la propia catedral como campaneros, pertigueros, perreros o músicos ministriles. Otras tantas están emparentados con los abastecedores del cabildo, rentistas o criados sin excluir a labradores y artesanos que veían así aliviada su economía personal y su prestigio con la estancia de sus hijos en el coro catedralicio. Puesto que el único condicionamiento inmediato era la posesión de buena voz para cantar, las posibilidades eran iguales para todos los aspirantes con la estimable perspectiva de que un puesto entre los infantes de coro suponía un porvenir prometedor, a juzgar por los hechos conocidos y la constatación histórica de que los grandes maestros de la música han sido antes niños de coro. En nuestro caso los nombres de Vitoria ", Cabezón ', Guerrero ${ }^{8}$ o Morales ", por citar los muy salientes, están documentados; pero las relaciones de maestros de capilla, organistas, cantores y ministriles aportadas por los musicólogos, citados en nuestro trabajo, confirman este supuesto, de modo definitivo, en razón de la preparación musical que recibían.

Para aquellos niños que, cumplido su servicio en el coro catedralicio, habían de salir fuera se les presentaba como solución el seguir la carrera eclesiástica, con preferencia sobre otros, disfrutando alguna beca colegial como sucedía en Palencia:

1 D. Mansilla, La Iglesia castellano-leonesa y Curia Romana en los tiempos del Rey San Fernando, Madrid 1945, 200.

'J. BlasCO, Historia y Derecho en la catedral de Segorbe, Valencia, 1973, 225.

- R. García-Villoslada y otros, Historia de la Iglesia en España, III-2.", Madrid $1980,575$.

S. KASTNER, Palencia, encrucijada de los organistas españoles del siglo XVI, "Anuario Musical» 14 (1959), 134.

" J. MOLL, Cristóbal Morules en España, "Anuario Musical» 8 (1953) 4-26.

"H. ANGLÈs, Cristóbal de Morales y Francisco de Guerrero, "Anuario Musical», 19 (1955), 56-105. 
pues entre las capitulaciones de la fundación del dicho seminario está asentado que se reciban los mozos de coro que hayan servido en esta catedral.. "."

En Huesca se les permitía estudiar tres años más "y en las Palmas, además de esto, se les seguía abonando un sueldo:

..después que los niños fueren grandes y ovieren perdido las boces que les den tres años de estudio a cada uno y ganen los ocho reales.. ${ }^{\text {? }}$

De cualquier modo, y como costumbre generalizada, a los niños que marchaban se les entregaba ropa, calzado y algún dinero para viático si los niños eran de otro lugar.

El derecho de admisión de los niños de coro se lo reservaba siempre el cabildo. Si esto no se tenía en cuenta, la reacción podría ser como la del cabildo de Burgos:

..y cuando nuevamente trajere el maestro de capilla alguno de los dichos seises, lo presente en el cabildo y canten en él para que si a los señores del cabildo les pareciere que se reciba, se recibe, y sino se vaya ${ }^{13}$.

Las pruebas de «sufficientia» para el ingreso de los niños consistían en el conocimiento de los rudimentos de leer, escribir y contar y, por supuesto, cantar. Así lo expresan los estatutos de Segorbe: tu ${ }^{14}$

..el precentor examinará de congrua litteratura in legendo pariter et in can-

Las pruebas de "vita et moribus» se aplicaban fundamentalemnte a los padres a través del informe del párroco y de algunos testigos fidedignos y, según apreciamos en los expedientes de ingreso, también a los niños de coro, como al resto de los miembros al servicio de la catedral se les aplicaba el examen de «puritate sanguinis». Estas dos exigencias se ven reflejadas en el Colegio de Infantes de San José de León en 1650, pues los niños que aspiren a ser admitidos en el colegio han de ser hijos legítimos de padres decentes ", y también en las actas capitulares de Osma:

10 A.C. Las Palmas fol.9, 11//III/1591. (1964), 33.

"A. Durán, La capilla de música en la catedral de Huesca, "Anuario Musical», 19

12 A.C. Palmas, 25/XI/1565.

"A.C. Burgos, s/d, 1548.

$14 \mathrm{~J}$. BLASCO, O.C., 118.

is ACL, doc. 10887, fol. 60v.-91v. 
..se recivió por infantico a un hijo de Pedro Martínez cerraxero y se le dió despacho de información ".

Otro bloque de pruebas "de integra salute» se basaba en la ley general para la admisión de clérigos al servicio de la iglesia por la que no habían de padecer enfermedad repugnante, contagiosa o mutilación grave. Hoy conocemos suficientemente el caso de los falsetistas u hombres tiples al servicio de las capillas catedralicias ante la prohibición expresa de intervenir directamente la mujer en los actos litúrgicos. Unas veces estos tiples lo eran por voz natural en canto de falsete o de cabeza, pero en muchas ocasiones eran jóvenes o adultos castrados como puede apreciarse en las actas capitulares de Santiago de Compostela, Salamanca, Palencia, Osma, Las Palmas, Badajoz, Sevilla etc. En la catedral de las Palmas parece que llegó a ser una costumbre, pues el cabildo determina que:

$$
\text { sia }{ }^{1} \text {.. } . \text {. escriba al arzobispo de Burgos para que envíe un tiple capón a esta igle- }
$$

Al tratar de estudiar la posibilidad de que los niños de coro pudieran ser admitidos, lo mismo que lo eran los adultos, para fomar el cuarteto básico de tiple, tenor, barítono y bajo, con esta mutilación, expone Durán Gudiol que las catedrales, como lo hacía la de Huesca, preferían niños castrados por la duración de 10 ó 12 años dentro del coro de infantes:

..los señores del capítulo resolvieron que el maestro de capilla vea si un muchacho capón que hay en Aniés tiene vóz y sabe leer y es de edad para servir de infante ${ }^{18}$.

y también la de Palencia los admitía:

..al caponcillo se le despida también con aquella decencia de vestidos que acostumbra esta Santa Iglesia ".

Aunque no sabemos con precisión cuál era la extensión de esta costumbre ni cuál el grado de rechazo social ante ella, sí podemos afirmar que, aunque las catedrales admitieron entre sus cantores a personas castradas, no consta documentalmente que estimularan o favorecieran este tipo de mutilación.

El procedimiento normal para cubrir las vacantes era la convocatoria o publicación de vacantes «ad valvas eclesiae» como se hacían con otras convoca-

16 A.C. Osma, 20/XII/1645.

17 A.C. Las Palmas, 3/VI/1589.

${ }_{18}$ A. DuRán, a.c., 33.

19 A.C. Pal. fol. 34, 31/VII/1979. 
torias catedralicias. Este sistema no siempre era suficiente, pues algunas catedrales se veían precisadas a mandar a sus maestros de capilla en busca de niños a otras regiones o escribir a otros lugares. La escasez estaba motivada por la lejanía y así el capítulo de las Palmas ordenaba: denal..

que se escriba a España que envien un tiple de Salamanca que se dice Car-

o por la pobreza para dotar las plazas como en Palencia:

..que Diego Mata el maestro de capilla vaja a la tierra de Astorga adonde se tenía noticia que había algunos niños de buenas voces ${ }^{21}$.

o por la escasez de voces o la existencia de buenos viveros, como sucedía en la catedral de Osma respecto de otros lugares conocidos:

..que se busquen infantejos en el obispado porque hay mucha necesidad y no allándose se busquen en Aragón o Navarra o en otros sitios de donde en otras ocasiones han venido ${ }^{22}$.

Al tratar de analizar cuál era la clase de centros y cuáles las formas de vida que en ellos llevaban los niños de coro, se nos ocurre, bien que como provisional, la distinción de tres distintos momentos históricos y tres nombres distintos en relación con una misma institución y un género de vida semejante, aunque sólo podamos ocuparnos de uno.

Existiría un primer momento entre los márgenes del siglo XII en que se van formando los cabildos de las diócesis recién restauradas hasta la definitiva secularización en el siglo XVI. El modelo de vida se ajustaba más al patrón monástico, pues el niño de coro era al mismo tiempo un donado al servicio del templo para desarrollar sumariamente unos posibles gérmenes vocacionales; era un acólito para las funciones litúrgicas y ayuda en la misa individual de los prebendados sacerdotes y también era un cantor en la salmodia coral. Estos niños vivían en la prepositura, deanato o algún lugar junto a los claustros catedralicios bajo la supervisión del precentor, según ya tenemos constatado. La vida de este puñado de pequeños, que nunca excedería de una docena, transcurriría entre las horas necesarias dedicadas al descanso, alimentación y juego moderado, y tal vez escaso, y entre las tareas del aprendizaje de las primeras letras, gramática, de la educación de la voz y el conocimiento de los géneros musicales suficientes para el canto coral y entre los otros servicios de carácter

21) A.C. Las Palmas, 3/X/1573.

21 A.C. Pal. fol. 6v., 29/I/1648.

22 A.C. Osma, 18/VIII/1649. 
litúrgico. No faltarían algunos otros menudos compromisos como el de los donados exomenses que:

habían de limpiar el polvo del sepulcro de San Pedro de Osma.. subir los asientos del coro y hacer la lectura durante la comida y cena de los capitulares.. ${ }^{23}$.

Por otra parte, este internado en las catedrales de Aragón con el nombre de precentoría o sucentoría abría también sus puertas a niños externos para las tareas musicales y de primeras letras, y así sucedía en Tarragona, Gerona o Valencia, pero no hemos encontrado esta situación en los centros primitivos catedralicios como los de Toledo, Salamanca, Santiago, Sigüenza y Osma sin que ello suponga negar que existiera.

Otra obligación que contrarían los cabildos con los niños de coro era la de procurar para ellos el vestido, calzado y hábito de los actos litúrgicos. El color rojo de los hábitos corales de los niños se había hecho común a casi todas las catedrales españolas con unos complementos parecidos a los utilizados en León:

Los niños lleven loba colorada con cuello alto y sobrepelliz almidonada, con mangas cumplidas y bonete negro ${ }^{24}$

Sin embargo en el reino de Aragón, cuyos canónigos lucían vestimenta coral roja, los matices en los niños eran también mayores como en Huesca:

..que en las funciones litúrgicas lleven los infantes sotana carmesí con botones de seda encarnada, roquete blanco circular con abertura en el centro y bonete de color grana ribeteado de cordón rojo.. ${ }^{25}$

mientras que en Orense se apunta un dato que también fue común a otras catedrales:

..llevarán los niños de coro ropas coloradas y roquete sin mangas pero cuando cambiaren de voz se les mudarán estas ropas por negras como lo acólitos.. ${ }^{26}$.

El cuidado del aseo se deja ver en ciertas prescripciones en cuanto al trato

${ }_{23}$ T. PORTILlO, Instituciones del Obispado de Osma, Almazán 1985, 184.

24 T. Villacorta, El Cabildo de León, León 1974, 179.

2s $\mathrm{ACH}$, Libro de Resoluciones, I, a/f.

${ }^{26}$ E. DURO, Las antiguas dignidades de la catedral de Orense, «Anuario de Estudios medievales» I (1964), 289-332. 
del pelo o la rasura de la corona, pues muchos de los niños tenían ya la primera tonsura clerical. En Osma se recomienda:

..que los infantejos se corten el pelo y anden con decencia y el aseo propio del ministerio al que están destinados ${ }^{27}$.

El orden y disciplina de los niños dentro del coro fue desde antiguo tarea específica del precentor o chantre y así los estatutos de Jaén de 1368 prescriben:

..Otro sí al oficio de chantre pertenece librar las querellas que acaescieren entre los infantes del coro e castigarlos de los yerros en que cayeren e develes apremiar que fagan rasura en tiempos devidos.. ${ }^{28}$.

Contener en quietud a los niños no sería tarea fácil y el lamento del chantre de Málaga sería común en muchos lugares: ro.. ${ }^{29}$,

..los niños no tienen sosiego y recogimiento que se debe tener en el co-

pero el P. Samuel Rubio, experimentado en estos trances, trata de justificar a los niños ante los ejemplos de otros miembros de la capilla:

Cómo se puede pedir quietud a los niños si un maestro como Juan Navarro propina una bofetada a un cantor de Salamanca; si un ministril golpea al maestro Juan Vidal de Arce con su corneta en la de Palencia; un organista desahoga sus iras en la catedral de Oviedo usando de sus manos «no para tañer» sino para herir «no teclas» sino el rostro de un pobre mozo de $\operatorname{coro}^{30}$.

Dentro de esta rigurosa disciplina existían los días de relajamiento como eran los asuetos semanales del jueves, las vacaciones navideñas y estivales y los días de representaciones y danzas en las que los niños intervenían. En el recinto de la catedral tenían especial relieve la fiesta del aguinaldo en que los canónigos obsequiaban, a modo de reyes magos, a los niños cantores y la fiesta del obispillo. Esta fiesta comenzaba ya en el día de San Nicolás y tenía su culminación la fiesta de los Inocentes. Desde su origen monástico llegó a ser común en todas las catedrales españolas. La catedral de Sevilla había dedicado uno de sus estatutos a regular esta fiesta:

27 A.C. Osma, 17/VI/1779.

${ }^{28}$ J. RodRíguez MOLINA, Estatutos de la catedral de Jaén en 1368, «Bol. de I.E.G.» 84 (1975)98.

29 A. LlORDEN, Notas históricas de los maestros de capilla en la catedral de Málaga, 1583-1641, 16 (1961) 71-93.

3) S. RUBIO, Historia de la Música, II, Madrid 1983, 39. 
..que la fiesta del obispillo se haga con dignidad pues es de tradición antigua..que vistan a un niño de obispillo y que los clérigos de veintena vayan con los mozos de coro y quatro mozos cantorcicos vestidos de seda y luego se haga pontifical con el obispo y obispillo (por el martirio de los Inocentes) pues para todo ello hay fundación de Juan Gómez de Sanoza que dejó mil maravedises.. "

No obstante, el riesgo de abusos también estaba presente como vemos reseñado en Palencia:

..que se supriman las celebraciones del día de los Inocentes por lo abusos que se han cometido en ellas ${ }^{32}$

pero esto no impedía para que este mismo cabildo mantuviera y dotara otra fiesta relacionada con los niños de coro:

..el cabildo ordena que se den 50 reales a los niños para la fiesta que hacen para correr los gallos.. ${ }^{33}$.

\section{UNA PEDAGOGÍA MUSICAL PARA NIÑOS CANTORES}

En el comienzo de este segundo apartado nuestra atención primera se ha de centrar en la figura del maestro o pedagogo musical. Ya conocemos la evolución histórica de este cargo y su cometido docente en cada momento, pero lógicamente surge una pregunta en torno a la preparación técnico-didáctica de estos maestros en relación con la enseñanza de los niños de coro. Sabemos que, a pesar de la presencia de algunos maestros de capilla en universidades, como la de Salamanca y Santiago, no consta que existiera título alguno expedido por éstas o por las escuelas superiores de música catedralicias, reconocido u homologable, que habilitara para la docencia en las capillas capitulares. Solamente un previo examen o un sistema variable de oposiciones sobre conocimientos musicales era la garantía para el ejercicio de la enseñanza en este campo. Suponemos, en primer lugar, que para el aprendizaje por parte de los niños del canto llano o gregoriano no se exigía al sochantre o sucentor, como doblero del chantre o precentor, un conocimiento ni extenso ni profundo del arte musical, pero el estudio de algunos ejercicios de oposición de los maestros de capilla, ya a

$"$ Estatutos y constituciones de la Santa Iglesia de Sevilla. 1513, Est. 27, B/n., Sec. $\mathrm{R} / 27.300$.

32 A.C. Las Palmas, 4v, 7/I/1547.

33 Ibid, fol. 90, 29/I/1547. 
partir del siglo XVI, van reuniendo una serie de exigencias técnicas como director, compositor, arreglador e interprete que suponen en muchos casos una excelente preparación. Es cierto que los criterios por los que se otorgan estas plazas, según consta en las actas capitulares, son excesivamente tipificados y poco técnicos al afirmar que un determinado maestro tenía "más suficiencia», "más experiencia», "más autoridad para regir y gobernar el facistol», que tenía "curso de enseñar" y también que en las oposiciones no existía un ejercicio específico para probar las cualidades didácticas para la enseñanza de la música a los niños de coro pero hemos de entender que la compentencia en este campo concreto solía ir en compañía de una buena formación musical ${ }^{34}$. Suponemos también que alguna fama negativa en relación con ciertos maestros de capilla procedía casi siempre de sus incumplimientos, abandono de obligaciones o veleidades personales que solían ser castigados con descuentos de haberes y el arrebatarles la enseñanza de los niños como castigo denigrante y así lo vemos reflejado, a título de ejemplo, en Huesca:

..que los infanticos se saquen de casa del maestro, porque el tal no cumple con su obligación de enseñarles y se les entreguen a mosen Nasarre con la obligación de que los trate muy bien y cuide de su enseñanza ${ }^{35}$.

Los tiempos destinados a la docencia, dentro de un reglamento-horario aparecen en los estatutos con cierta precisión en un apartado que se dedica al maestro de capilla. En la determinación de las horas se observa con cierta claridad que existen unos momentos, en concepto de ensayo, con toda la capilla de cantores y con los canónigos, beneficiados, bachilleres y niños antes o después de las horas canónicas y en la catedral por lo común, y que existen otros momentos de preparación exclusiva para la formación musical de los niños de coro. La duración de estos tiempos docentes será una hora diaria en Málaga:

el maestro de capilla está obligado a dar lección por espacio de una hora contínua todos los días, excepto los domingos y días de fiesta, so pena que en el día que no la diere fuese multado en pan y maravedises de aquel día ${ }^{36}$

pero en las Palmas serán dos horas, la una entre prima y tercia y la otra entre nona y vísperas ". En Sigüenza la dedicación aumenta con una hora de canto antes de las horas menores a los niños, otra antes de vísperas y una tercera

4J. ARTero, Oposiciones al Magisterio de Capilla en España durante el siglo XVIII, "Anuario Musical» 2 (1947), 191-212.

is ACH, Resol. II, 11/9/1609.

is A.C. Málaga, núm. 14, fol. 29, 1/9/1539.

"A.C. Las Palmas, 2/VII. 
de «exercicios» después de completas ${ }^{38}$ y en Oviedo se señala una hora nocturna que suponemos coincide con la anterior disposición de la catedral seguntina:

item que de todos los Santos hasta primero de marzo dé lection de noche a los mozos de coro una hora de órgano y contrapunto ${ }^{39}$.

Según los reglamentos de los colegios de infantes podemos observar que el horario dedicado a la enseñanza de los niños está mejor organizado y es tal vez más amplio.

La metodología y el conjunto de recursos y estrategias técnicas para la enseñanza del canto a los niños de coro venían en parte dadas por la tradición de las escuelas de música y capillas polifónicas y estaban recogidas en vademecums o artes musicales que los propios maestros de capilla solían manejar como preparación para sus propias oposiciones pero no hay que descartar, por otra parte, la iniciativa personal y la experiencia pedagógica de estos mismos maestros adquirida en el oficio constante y en el trato con los niños. En este sentido, una primera observación sobre las aptitudes distintas, diferentes edades o fechas de entrada en el coro de los niños obligaba al maestro de capilla a una educación individualizada y personal con la mira puesta hacia una integración y puesta a punto para la intervención en los ensayos y actuaciones de la capilla o del resto de niños cantores. Esta consideración nuestra se ve reflejada en el largo capítulo de obligaciones que el maestro de capilla de León, Lucas Tercero, ha de tener en cuenta para ejercer dignamente su cargo:

...el maestro acabadas las horas ha de ir a la capilla haciendo con todos los niños exercicios con los que más viere que conviene.. y a la una irán a su casa adonde cantarán y harán exercicio conforme viere que es menester.. y desde Pascua Florida a los Santos.. a la una y media.. tendrán el exercicio que le pareciere mejor para su enseñanza.. "to.

La aplicación de distintas estrategias metodológicas en el proceso de la enseñanza de la música corre paralela a las distintas etapas o espacios de aprendizaje que con más o menos uniformidad reflejan los llamados libros del arte musical.

Una primera etapa en la formación del niño cantor lo constituían los llamados «rudimentos» que consistían nada menos que en la educación de la voz y del oído con un adiestramiento en la lectura musical y el solfeo para lo que el maestro se ayudaba de un órgano portátil o armonio situado en alguna de las

${ }^{38}$ Estatutos, Reglas de Coro, Sigüenza, tit. III.

39 Estatutos y constituciones, Oviedo, fol. 14.

41" J.M. Álvarez Pérez, La Polifonía Sagrada y sus maestros en la catedral de León durante el siglo XVII, "Anuario Musical» 10 (1957) 154. 
capillas de la catedral o en su propia casa. El maestro de capilla comenzaba enseñando al niño, en términos para éste comprensibles, que la articulación de una nota musical, con vocales y consonantes exigía una apertura y localización adecuada dentro de la boca.. que los órganos de fonación generadores del sonido, como las cuerdas vocales, la lengua, los labios, tenían una caja de resonancia en la cavidad bucal y la caja torácica manteniendo y regulando la intensidad y extensión del sonido desde el piano hasta el fuerte..que un ánimo tranquilo, el cuerpo recto y relajado y una actitud distendida ayudaban mucho a la buena práctica del canto. El maestro de capilla sabía que un ejercicio gradual y continuado sobre saltos de cuartas y quintas, sobre corridos de escalas y arpegios, juegos de trinos, gorgeos y toda clase de "fiorituri» conseguían afinar el oído, impostar "colocar la voz» del niño y que aquellas voces blancas «sin color» de sopranos ( $\mathrm{sol} 2$ - $\mathrm{fa}$ 4) y de contraltos (mi 3 - re 4) podían superar esta tesitura normal ganando en altura, timbre y volumen. El complemento de este aprendizaje preparatorio era el dominio elemental del canto llano, gregoriano o "cantus firmus» con sus claves, kilismas, neumas, tonos y fraseos, y del canto figurado conociendo los compases, aires, figuras, silencios y alteraciones, ritmos, melodía y dúos. Pero esta árdua tarea había de realizarla el maestro de capilla, según reflejan algunas actas o contratos de trabajo musical, en cuatro meses y así señalan los estatutos de Burgos que la preparación de los niños no ha de durar más allá de éstos para "estar bonicamente enseñados», y en la catedral de las Palmas escriben:

..mandaron notificar -los dichos señores- que dentro de cuatro meses sepan cantar.. y no cantando lo que les fuere encomendado que no ganarán cosa de su renta hasta que lo sepan ${ }^{41}$.

Aun pensando que no fuera ésta la postura más generalizada, también observamos que las actas, escritas tal vez por secretarios no diestros en terminología musical, no reconocen el trabajo del maestro de capilla y se reducen a frases laudatorias como éstas: «el maestro ha sacado buenas voces de los niños», «era hábil para hacer voces de niño», "ya cuenta con un coro de ángeles en su capilla» o a esta más peregrina interpretación al prohibir a un niño que baje a los oficios de la noche "por ser muy buena voz y no se gaste" ${ }^{42}$.

En un segunda etapa el maestro adiestraba al niño en el conocimiento e interpretación de los géneros musicales catedralicios dentro de los necesarios matices de color, viveza, dominio y religiosidad. En los capítulos dedicados al maestro de capilla, dentro de los estatutos de la catedral de Burgos, encontra-

41 A.C. Las Palmas, 22/XI/1529.

22 P. Calahorra, Historia de la Música en Aragón, Zaragoza 1972, 162. 
mos unas normas pedagógicas que afectan claramente a esta etapa, copiadas, y en cierto modo interpretadas, por Samuel Rubio:

..se advierte que los niños se dividan en grupos atendiendo al grado de sus conocimientos.. han de comenzar por el canto llano enseñándoles los tonos en la mano y en el libro..que tengan por costumbre repetir cada día la lección del precedente, exigiéndoles cuenta de ella y no pasando a la siguiente sin haber dominado la anterior..luego comenzarán el canto de órgano y ésto con mucha furia, sin dejar el canto llano cuya práctica simultánea acarreará beneficio recíproco. Cada alumno tendrá su cuaderno. En él escribirá las figuras, las pautas y las ligaduras. En cuanto vayan adquiriendo un poco de dominio les mandará sacar de los libros de atril dúos, tríos y algunos versos del magníficat. Pasarán luego a cantar de muy buen aire y con toda osadía..e como los dichos niños estén un poco diestros en el canto de órgano luego el dicho maestro les ponga en darles lección de contrapunto porque ésto es con lo que acaban de hazerse hábiles y el cómo se tiene de dar y enseñar no se pone aquí la forma porque hay diferentes modos de ello.. ${ }^{43}$

Pero a estos aprendizajes curriculares del «cantus firmus» o canto llano, del "cantus novus» o polifónico, del "discantus» o contrapunto se añadían en algunos casos ejercicios de composición. Esto sucedería en catedrales en las que la capilla estaba respaldada por una escuela musical superior. En los estatutos de la de Oviedo se lee:

..a los mozos de coro y cantores dé lection de contrapunto y enseñeles compostura a los que para ello tuvieren habilidad.. ${ }^{41}$

y en la catedral de Sevilla, tal vez aprovechando la presencia, como maestro de capilla, de Francisco Guerero, se exige:

item les enseñe cantar canto llano, canto de órgano y contrapunto y les enseñe a componer y otras habilidades que para ser diestros músicos y cantores conviene que sepan los dichos niños cantorcicos ${ }^{45}$.

Confirmando una afirmación anterior nuestra encontramos documentado cómo Tomás Luis de Vitoria, que entró a los diez años como niño de coro en la catedral de Ávila, bajo la dirección de los maestros Bernardino de Rivera y de Juan Navarro, aprendió allí todos los secretos de la música de modo que cuando a los 19 años marcha a Roma domina perfectamente la composición y la interpretación de órgano ${ }^{46}$.

S. Rubio, o.c., 37.

"Estatutos y constituciones, Oviedo, fol. 15.

45 H. ANGLÈS, Cristóbal de Morales, o.c., 63.

* R. García-Villoslada y otros, Historia, o.c. III-2. ${ }^{\circ}, 575$. 
Además de estas enseñanzas cantuales encontramos cómo en algunas catedrales, tal vez por dar una continuidad musical a los niños, por proporcionales un mantenimiento económico o ante la estrechez de ministriles, se enseñaba también a éstos a tocar determinados instrumentos. En Plasencia se señala:

..que a los mozos de coro que tengan habilidad y parezcan que pueda salir buenos tañedores se les enseñe.. ${ }^{\text {t }}$

en Las Palmas, además del órgano como en la anterior, se advierte:

..los mozos de coro que se mombraron para teñer violines se queden con el salario que tienen ${ }^{48}$

pero en Osma, tal vez por necesidad, los niños aprenden más instrumentos:

..el infantejo Regaño está aprendiendo la trompa, que el Rosillo siga aprendiendo el órgano y el violín al que está dedicado y que prepare a otros niños para aprender instrumentos.. ${ }^{49}$.

Otra de las cargas docentes del maestro de capilla, además de la musical, consistía en la preparación de los niños de coro en las primeras letras y en la gramática latina. En cuanto a la primera obligación, ya tenemos adelantado la conexión de las escuelas de canto con las de primeras letras y posteriormente encontramos en los estatutos catedralicios, señalada como una obligación más del maestro de capilla, la de enseñar a leer y escribir a los niños de coro. Por otra parte la enseñanza de la gramática en las catedrales se normaliza a través de las disposiciones de los Concilios de Letrán III (1179.c.18) y IV (1215.c.11) por medio del maestrescuela o su doblero con la carga de enseñar este arte a los clérigos pobres de la catedral; pero lógicamente ésta también se extendería a los niños de coro como un elemento necesario para el canto latino de la salmodia. Esta necesidad se ve reflejada, incluso antes del propio Concilio III de Letrán, en Santiago de Compostela, cuyas aulas de gramática ya tenemos reseñadas, por una determinación capitular de 29 de julio de 1170 :

..que el maestrescuela ponga un preceptor que enseñe gramática no sólo a los clérigos y niños de coro sino a los de la ciudad.. ".

47 Estatutos de la Santa Iglesia Cathedral de Plasencia bechos por Don Andrés de Norona, Madrid 1704, tit. Mtro. Capilla.

48 A.C. Las Palmas, 3/VI/1598.

49) A.C. Osma, 21/IV/1800.

so S. TAFALL, La capilla de música de la catedral de Santiago, «Bol. de la Real Academia Gallega», 230 (1931) 28. 
Así continuaría esta enseñanza de la gramática a los niños de coro en las aulas catedralicias bajo el maestrescuela hasta el último tercio del siglo XVI en que algunas de éstas pasaron a los seminarios tridentinos con sus dotaciones y maestros y otras a los colegios de jesuitas cedidas también por los mismos capitulares ". En esa situación pasaron estas enseñanzas también el maestro de capilla. Los estatutos de Ávila señalan esta circunstancia "2, pero sobre todo serían los colegios de infantes, que van apareciendo en el siglo XVII, los que aportan con más claridad este dato. Así en Burgos, cuyo gobierno ostentaba el maestro de Capilla:

..a sus colegiales no sólo se les instruía en la música sino también en los rudimentos de gramática.. "3

y también en el de San José de León, donde se establece una preceptoría de gramática $^{54}$, y en el Colegio de S. Pedro de Osma, en el que se advierte al maestro de capilla:

que se dé lección diaria a latín a los mozos de coro".

Un aspecto, nada desdeñable, en la formación musical de los niños de coro lo componen los medios o instrumentación didáctica como serían los libros, lugares de ensayo y actuación o el órgano catedralicio.

La existencia de un armario de música y las obligaciones por parte del maestro de capilla de cuidar del mismo es un dato común en toda la documentación capitular.

Tomando como modelo la catedral de León leemos:

Ha de tener -el maestro de capilla- a su cargo los libros que hubiere de música, mandando a uno de los muchachos del coro que hubiere en su casa, los guarde en uno de los cajones que para eso hay en la capilla que estará señalada para cantar... procurando que haya en ella libros de canto llano y de órgano los que sean menester para cantar y enseñar a todos ${ }^{36}$.

Los libros que fundamentalmente contenía el armario eran libros de

"B.BARTOLOMÉ, Las escuelas de gramática, en Diccionario de Historia Eclesiástica de España, V, Madrid 1987, 285-299. 1966, 89 .

32 J.R. LOPEZ-ArÉvalo, Un Cabildo catedral de la Vieja Castilla: Ávila, Madrid

33 BRAH Col. Velázquez, Sign. 9/5041.

st ACL., doc. 10, 916. o.c.

"A.C. Osma, 8/XI/1787.

so J. M." Álvarez Pérez, a.c., 153. 
enseñanza del maestro o artes de música, libros de canto de coro y salmódico y libros de interpretación sinfónica e instrumental.

La importancia de los libros de enseñanza musical o libros de arte musical como instrumento y ayuda del maestro de capilla está refrendada por el gran número de los existentes aunque no sea la originalidad la nota sobresaliente. Ya Higini Anglès en uno de sus magníficos trabajos de investigación señala la existencia en las catedrales españolas de libros de arte musical, a veces procedentes de los monasterios de Ripoll o de San Juan de la Peña, pero siempre influenciados por las corrientes musicales surgidas luego en los ambientes artísticos de los Concilios de Costanza o Ferrara, de las aportaciones flamencas y francesas desde el "Ars Antiqua" al "Ars Nova", desde las capillas papales, arzobispales y reales o palatinas, ". Una mínima relación de este tipo de libros histórico-didácticos nos deja cumplido nuestro deber de insistir en estos libros de texto para el estudio y enseñanza de la música. Muy utilizados fueron el «Ars cantus plani portus musicae» (Salam., 1504) de Alfonso del Castillo, «Libro de músico práctica» (Barcel., 1510) de Francisco Tovar, el menos original ${ }^{\text {s8 }}$ "Vergel de Música spiritual speculativa y actiua» de Tapia Numantino (Burgo de Osma, 1570), "Arte de canto llano y canto de órgano" (Vallad., 1592) de Francisco Montanos, "Laura de Música eclesiástica» (Madrid, 1644) de Juan Ruiz de Robledo y la "Llave de la modulación o antiguedades de la música» (Madrid, 1752) del P. Antonio Soler.

Un segundo bloque de libros del armario intitulados «liber chori» 0 «liber usualis» contenían la liturgia cantual. La participación de los niños de coro en la salmodia canonical está ya desde antiguo comprobada en los reservados que para ellos hacen libros tan famosos como los códices de canto eugeniano de Toledo, el Codex Calixtinus o el Missale Oscense. Otros libros manuales como los kyriales, vesperales, hebdomadarios, rituales, passionarios o misales, que manejaban los maestros de capilla con los niños, tienen marcados los trozos que éstos habían de aprender e interpretar. En ocasiones, los mismos maestros de capilla escribían libros manuales en conformidad con el rito o costumbres de una catedral concreta:

Breve instrucción de canto llano, como para cantar epístolas, lecciones, prefacios y evangelios y otras cosas que se cantan conforme al estilo de la Santa Iglesia de Sevilla ordenada por Luis de Villafranca maestro de los mozos de coro de la dicha Iglesia. Con licencia. Sevilla. 1565

y de la misma manera observamos que en Huesca mosén Olorón, capiscol

"H. ANGLÈs, De cantu Organico. Tratado de un autor catalán del siglo XIV, en Scripta Musicologica, 3 vols, Roma 1977, 1321-1333.

${ }^{58}$ F. LEÓN TELLO, Un caso de plagio en el siglo XVI, "Clavileño» (1955). 
de la catedral, hace un libro de «Intonación de innarios y nocturnos conforme al uso de esta Iglesia»".

Entre un tercer grupo de libros encontramos composiciones polifónicas impresas y manuscritas de misas, motetes, ofertorios con acompañamientos de voces y órgano, y un número indefinido de tientos, variaciones, conciertos y piezas acomadadas a las características de la organería de los siglos XVI al XVIII. Los abastecedores de estas músicas, entre otros, eran Palestrina, Vitoria, Francisco Guerrero, Morales, Fernando de las Infantas, Juan Navarro, Fernando Barrientos, Cristóbal de Isla, Antonio de Yanguas, Cepeda. Las Actas capitulares de todos los cabildos que hemos consultado, correspondientes a la segunda mitad del siglo XVI, demuestran una especial sensibilidad musical cuando en noble emulación solicitan copias de las obras de Vitoria, Morales y Guerrero, y los libros de fábrica en este mismo sentido testifican de pagos al «escribano", «copiador», "escritor», «apedazador», «encuadernador», «remendador», "facedor» y "editor» de libros de música y canto.

El lugar donde tenían comúnmente sus ejercicios y ensayos los niños de coro serían algunas de las capillas laterales a la nave principal de la catedral, destinada como hemos observado ya a la práctica de la música y al armario de obras, aunque en otros documentos se nombran los claustros, sin olvidar en este sentido que en Toledo al maestro de capilla o maestro de música se le llamaba claustrero ${ }^{61}$. El instrumento regulador y acompañante del canto sería básicamente alguno de los órganos instalados en el coro o algún otro instrumento portátil de teclado.

Dentro de lo que venimos llamando «aspectos pedagógicos» hemos de poner de relieve aquellos momentos y solemnidades en que la presencia y actuación de los niños de coro se dejaba ver de modo preferente. Un primer cometido, reservado a los niños y según los estatutos, era el canto de la «kalenda» o proclamación de la categoría litúrgica del día que éstos solían realizar por semanas y que previamente había de ser ensayada por el maestro de capilla, como se anota en los exomenses:

... los niños de coro siempre leerán la kalenda antes de cantarla con toda claridad evitando malos acentos o serán multados y también si erraren en echar las fiestas ${ }^{\text {"1. }}$.

Otras intervenciones de los niños en el coro quedaban al arbitrio del

s9 A.C.H. Resol. I. foc. 31v., 13/VII/1569.

(1) F. RubiO, Música y músicos toledanos, «Bol. de la Real Academia de Bellas Artes de Toledo», 10 (1972), 161.

${ }^{61}$ Reglas de Coro y cabildo de la Santa Iglesia de Osma, Madrid 1681, tit. Mtro. Capi$11 \mathrm{a}$. 
director del mismo. Así en Toledo, dice Rubio Piqueras que los infantes de coro eran los encargados de cantar el gradual y el aleluya de la misa "por la flexibilidad, trinado y facilidad para pegarse al oido" ${ }^{62}$ y para la catedral de Pamplona descubre Goñi Gaztambide la costumbre de cantar los niños la misa de aurora en la capilla de Santa Catalina ${ }^{63}$ como sucedía en otras iglesias de Aragón. De cualquier modo los niños solían siempre actuar como solistas en los versículos, antífonas o solos de voz blanca en la polifonía y en cualquier momento en que el brillo o la penetración de sus interpretaciones pudiera ayudar al esplendor litúrgico.

La «consueta u ordo chori» de algunas catedrales señalan los días en que los niños de coro han de asistir a la solemnidad, coincidiendo ésta con los tiempos fuertes del Adviento y Navidad, de la Cuaresma y Semana Santa, Ascensión, Pentecostés y Corpus, además de las festividades mayores de la Virgen y los Santos. Como modelos podríamos señalar la costumbre de algunas catedrales; y así la de Huesca, bajo el epígrafe «cuándo ha de sonar el órgano», distingue entre las distintas categorías de fiesta ${ }^{64}$, y la de León puntaliza las interpretaciones polifónicas de motetes, cantos procesionales, momentos eucarísticos según el rango festivo "; mientras que en Pamplona es el número de capas utilizadas en la solemnidad lo que determina el número de intervenciones, señalando que en el día de seis capas «todo será a canto de órgano menos los responsorios que los dicen los seises» ${ }^{66}$.

Las normas del coro señalan también como actuación de los mozos de coro la asistencia y canto al facistol. Se trata de un atril monumental en forma de pirámide sobre un soporte giratorio, tallado siempre en maderas nobles. Sobre cada una de sus caras se mantenían abiertos cuatro cantorales para la lectura común de los coros cantores desde cualquier ángulo del recinto. La obligación de los niños era el paso oportuno o vuelta «versus» o la espera cuando se trataba de caras seguidas "prorsus» o prosa; pero esta operación, además de justificar como origen etimológico las dos formas literarias en uso, habría de hacerse con esmero y puntualidad como señalan los estatutos de Jaén porque:

...deven ansimesmo assistir al facistol los mozos de coro todo el tiempo que durare el oficio divino para volver la ojas a tiempo y el facistol y ésto con mucho cuidado sin distraerse porque si no se bueluen las ojas puntualmente haze falta a los que cantan y continuamente todos se inquietan ${ }^{67}$

62 F. Rubio., a.c., 227. $3-42$.

(3) J. GoÑI, La Capilla musical de la Catedral de Pamplona, Pamplona 1983,

${ }^{64}$ A. DURÁN, a.c., 50.

6) J. Álvarez PÉREZ, a.c., 144.

G J. GoÑI, o.c., 27.

67 Libro de Estatutos, Jaén, o.c., tit. Mtro. Capilla. 
y en estos estatutos también se señala el lugar donde se interpretaba la polifonia y la obligación de que los niños de coro canten allí:

$$
\begin{aligned}
& \text { item todos los clerizones quando assitan al facistol deuen cantar y ayudar al } \\
& \text { coro }{ }^{68} \text {. }
\end{aligned}
$$

Un momento importante de actuación del niño de coro, que hemos venido señalando ya con frecuencia, es la capilla catedralicia con la institución paralela y alimentadora que era la escuela superior de musica. La capilla catedralicia debía casi siempre su florecimiento a la abundancia de sus rentas o al esfuerzo especial de los respectivos cabildos, pero en España y a partir del siglo XVI, se encuentran historiadas bastantes de las más florecientes como las de Valencia, Gerona, Huesca, Zaragoza y Pamplona en el reino de Aragón y la de Santiago, Oviedo, Salamanca, León, Burgos, Osma, Palencia, Toledo, Badajoz, Sevilla, Granada y Málaga en el de Castilla, según citas de nuestro trabajo. Además de las 12 o 14 raciones de cantores en algunas de ellas, se habían de sumar los clérigos cantores, capellanes, clérigos de veintena, bachilleres de coro y hasta los alumnos del seminario, situado "prope ecclesiam» por el concilio de Trento para aprendizaje y servicio al culto catedralicio, todos ellos bajo la dirección del maestro de capilla y para interpretar la polifonía sagrada ante el pueblo con el acompañamiento de los instrumentos musicales. Estos también estaban regulados con un capítulo aparte en los estatutos en los que se habla del organista y de obligaciones de los instrumentistas de metal como la corneta, el figle, la trompa, el sacabuche (especie de trombón de varas); de los ministriles de la cuerda como los violines, arpas, bajones; o de madera como la flauta, chirimía. En las actuaciones de la capilla polifónica las voces blancas de los niños de coro en número de 6 o 12, y hasta 25 en alguna ocasión, llevando el «altus» de la partitura, eran una parte imprescindible de la interpretación litúrgico-cantual. Pero ciertamente la fuente y el soporte de todo este movimiento musical lo constituían las escuelas catedralicias de música superior, que si nunca de modo oficial ostentaron este nombre, en realidad y en palabras de José M." Álvarez Pérez, investigador sobre la música catedralicia de León:

...el maestro de capilla tenía a su disposición una verdadera cátedra de su magisterio... lo que hoy es una escuela de música sagrada existía en nuestras catedrales ${ }^{69}$.

Fuentes documentales que utiliza Sanchís Sivera localizan una escuela de

68 Ibid.

69 J. Álvarez PÉrez, a.c., 141. 
música superior, ya en el siglo XIV, para la catedral de Valencia ", y Rubio Piqueras defiende este mismo planteamiento para Toledo ", lo mismo que Pedro Calahorra al hablar de una escuela de polifonía para la Seo de Zaragoza ". En Burgos ya hemos situado un centro de enseñanza musical como abastecedor de músicos para muchas catedrales de España ${ }^{73} y$ en este apartado cabría también situar la fundación del arcediano Pedro de Bolea, que en el siglo $\mathrm{XV}$ ya pone a disposición de la Catedral de Huesca lo que Gudiol Durán califica como escuela de música ${ }^{74}$.

\section{BERNABÉ BARTOLOMÉ MARTÍNEZ Facultad de Geografía e Historia Universidad Complutense (Madrid)}

\section{RÉSUMÉ}

Ce travail prétend faire apparaître le rôle, dans les cathédrales espagnoles, de l'activité éducatrice dans le domaine de la culture musicale, sur un secteur choisi de l'enfance.

Dans une première partie, nous essayons de voir le rôle historique joué par la figure du maître éducateur des petits chanteurs en tant que directeur de toute l'activité musicale dans les cathédrales. Nous étudions, à propos de ces enfants, l'origine de leur nom, les critères de sélection pour leur acceptation dans le choeur, leur origine sociale et la règlementation de la vie en internat et ceci, à travers les statuts de la cathédrale.

Dans une deuxième partie, nous attirons l'attention sur l'historial de l'enseignement musical, le temps dédié à l'apprentissage et les interventions musicales postérieures des enfants de choeur lors des fonctions liturgiques. Nous analysons les méthodes et les stratégies utilisées au cours de la préparation corporelle, psychologique et technique qui a une influence permanente sur le rendement adéquat en ce qui concerne le chant. La personne qui travaille et enseigne directement à l'enfant ces techniques est le maître de chapelle du chapitre de la cathédrale. Les débuts incertains de l'étape médiévale culminèrent, déjà au moment de la renaissance, dans la scolaristation de ces enfants dans des centres spécialisés qui étaient connus à l'époque comme écoles d'enfants.

71 J. SANCHís, La enseñanza en Valencia en la época foral, «Bol. de la Real Academia de la Historia», 108 (1936), 177.

7 F. Rubio, o.c., 203.

72 P. CALAHORRA, O.C., 721.

"3 BRAH, Col. Velázquez, o.c., 187.

7 A. DURÁN, o.c., 36. 


\section{SUMMARY}

This work tries to discover, in the Spanish cathedrals, the educational activity in musical culture for a chosen section of the childhood.

In the first part of the study, we look back at the history of the character of educational master of the singing boys in his charge of director of all the musical activity within the cathedrals. In relation with these children, we study the origin of their name, the criteria of selection used for their entry in the choir, their social origin and the rules of the life in the boarding school, through the status of the cathedral.

In the second part of the study, we draw the attention on the music educational curriculum, the timing of learning and the following singing interventions of the choirboys during the liturgical functions. We analyze the methods and strategies followed as far as the corporal, psychological and technical preparation is concerned that have an influence in the most adequate efficiency of their singing activity. The character that works and teaches these abilities directly to the child is the master of chapel of the cathedral area. The vague beginnings of the medieval step reached their peak, already in the Renaissance, in providing many boys with schooling in specialised centres, already known under the name of children schools. 